05

\title{
Разработка износостойких нанокомпозитов для экстремальных условий эксплуатации в металлополимерных трибосистемах
}

\author{
(C) Ю.К. Машков, О.В. Чемисенко, О.В. Малий \\ Омский государственный технический университет, \\ 644050 Омск, Россия \\ ฯ e-mail: malij_olga@mail.ru
}

(Поступило в Редакцию 25 мая 2017 г.)

Рассмотрены результаты разработки и исследования структуры и свойств полимерных композиционных материалов триботехнического назначения на основе политетрафторэтилена с наномодификаторами различного состава.

DOI: $10.21883 /$ JTF.2018.01.45479.2360

Анализ работ в области триботехнического материаловедения показывает, что для уплотнительных элементов металлополимерных герметизирующих устройств и подшипников скольжения, дорожно-строительных, транспортных машин и других видов техники необходимы полимерные композиционные материалы (ПКМ), обладающие высокой прочностью и износостойкостью при относительно невысокой жесткости. Детали узлов трения машин, изготовленные из полимерных материалов, имеют меньшую массу, работают практически бесшумно, обладают демпфирующей способностью, в ряде случаев не требуют смазки. Поэтому работоспособность многих металлополимерных пар трения существенным образом зависит от свойств используемых модификаторов, которые определяют условия теплоотвода, распределение нагрузки, а также снижают колебания основных конструктивных элементов многих машин [1-4].

Работоспособность и долговечность многих металлополимерных узлов трения (трибосистем) существенно зависят от свойств наполнителей модификаторов ПКМ, которые влияют на условия и эффективность теплоотвода, распределение нагрузок, снижение колебаний и демпфирования элементов конструкции, например ходовой части гусеничных машин. В отличие от металлов ПКМ обладают улучшенными диссипативными свойствами, снижая энергонапряженность технических систем, что особенно важно для систем, работающих в широком интервале повышенных температур при значительных динамических нагрузках.

Синтез полимерных нанокомпозитов, отличающихся высокой износостойкостью, возможен методом многоуровневой структурной модификации полимеров путем введения в полимерную матрицу наполнителей модификаторов различной природы формы и размера частиц: волокнистых, полидиссперсных и наноразмерных $[5,6]$.

В запатентованном ПКМ [6] комплексный модификатор содержит микроразмерные порошки дисульфида молибдена и скрытокристаллического графита (СКГ), а также углеродные нанотрубки (УНТ). С целью изучения эффективности различных модификаторов проводили сравнительные испытания на машине трения образцов ПКМ двух видов без дисульфида молибдена [7]. Один ПКМ содержал СКГ и УНТ, второй - СКГ и наноразмерный порошок диоксида кремния марки БС-120 [8]. Результаты испытаний показали, что наименьшую скорость изнашивания обеспечивают образцы с диоксидом кремния. При этом оба вида ПКМ имеют практически одинаковый предел прочности при растяжении, а модуль упругости ПКМ с модификатором БС-120 на 27\% ниже. Это обстоятельство свидетельствует о целесообразности применения в металлополимерных узлах трения ПКМ с диоксидом кремния вместо УНТ. В то же время углеродные модификаторы характеризуются высокой теплопроводностью, следовательно, с целью повышения диссипации, генерируемой в зоне трения тепловой энергии, целесообразно использовать углеродные модификаторы в композитах триботехнического назначения.

На основании изложенного изготавливали и исследовали образцы полимерных нанокомпозитов с комплексными наполнителями, содержащими наноразмерные диоксид кремния марки БС-120 в количестве от $4.0 \mathrm{wt} \%$ и технический углерод (ТУ) марки N220 [9] в количестве от 1.0 до $3.0 \mathrm{wt} \%$ Исследование характеристик механических свойств проводили на разрывной машине Zwick/Roell по методике ГОСТ 1126280. Результаты исследования нанокомпозитов показали, что предел прочности и модуль упругости имеют наибольшее значение при растяжении. Увеличение концентрации ТУ $\mathrm{N}-220$ - от 2.0 до $3.0 \mathrm{wt} . \%$ приводит к снижению предела прочности и модуля упругости на $25-27 \%$.

С учетом полученных значений характеристик механических свойств для исследования износостойкости разрабатываемого нанокомпозита были изготовлены образцы с постоянной концентрацией ТУ марки N-202 $2.0 \mathrm{wt} . \%$, и с изменяемой от 1.0 до $6.0 \mathrm{wt} \% \%$ концентрацией диоксида кремния марки БС-120. Испытания образцов проводили на машине трения УМТ-2168 по схеме трение „палец-диск“ без смазки при скорости скольжения $1.2 \mathrm{~m} / \mathrm{s}$ и контактном давлениеи $2.66 \mathrm{MPa}$. 


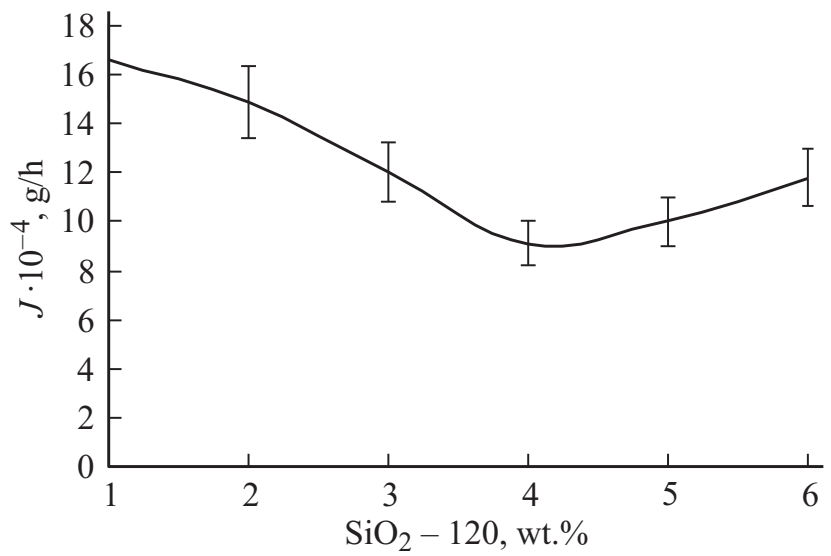

Рис. 1. Концентрационная зависимость скорости изнашивания ПТФЭ нанокомпозита.

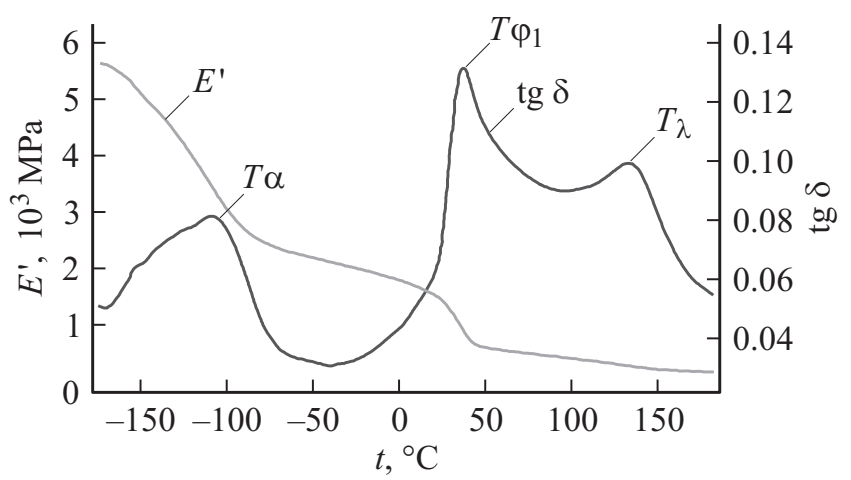

Рис. 2. Температурные зависимости характеристик вязкоупругих свойств ПКМ с ТУ марки N-220 - 2.0 wt.\% и диоксида кремния БС-120 - 4.0 wt.\%; $E$ - динамический модуль Юнга; $\operatorname{tg} \delta-$ тангенс угла механических потерь.

Полученная зависимость скорости изнашивания от концентрации модификатора БС-120 (рис. 1) имеет нелинейный характер.

Минимальная скорость изнашивания наблюдается при концентрации БС-120 $4.0 \mathrm{wt. \%}$ Следовательно, при концентрации ТУ $\mathrm{N}-220 \quad 2.0 \mathrm{wt} . \%$ содержание БС-120 в количестве $4.0 \mathrm{wt} . \%$ можно считать оптимальным. Для дальнейшего снижения скорости изнашивания целесообразно использовать запатентованные способы изготовления изделий из ПКМ на основе ПТФЭ [10,11].

Важное значение, определяющее область применения ПКМ триботехнического назначения, имеют характеристики их динамических свойств. Известно, что ходовая часть транспортных и других машин работает в условиях высоких динамических нагрузок в широком интервале температур. В названных условиях работают и уплотнительные элементы герметизирующих устройств, например, опорных и направляющих катков гусеничных машин, изготавливаемые из ПКМ.

В этой связи методом динамического механического анализа исследовали температурные зависимости дина- мического модуля упругости разрабатываемого нанокомпозита в интервале температур от -170 до $+180^{\circ} \mathrm{C}$.

На рис. 2 приведены температурные зависимости динамического модуля Юнга и тангенса угла механических потерь, полученные при одноосных вынужденных колебаниях с частотой $1 \mathrm{~Hz}$ при амплитуде $20 \mu$ m на приборе динамического механического анализа DMA 242 C.

Из рисунка видно, что температурная зависимость динамического модуля Юнга имеет нелинейный характер, резко снижается в интервале температур от -170 до $-95^{\circ} \mathrm{C}$ и при дальнейшем повышении температуры интенсивность снижения $E^{\prime}$ уменьшается примерно в 4 раза. При этом $T_{\alpha}-$ температура релаксационного перехода механического стеклования полимерной матрицы находится в области низких отрицательных температур $-110^{\circ} \mathrm{C}$, а $T_{f 1}-$ температура фазового перехода в области положительных температур при $40^{\circ} \mathrm{C}$. Это свидетельствует о том, что работоспособность нанокомпозита сохраняется в широком интервале положительных и отрицательных температур от -110 до $+180^{\circ} \mathrm{C}$.

Исследование надмолекулярной структуры нанокомпозита методом растровой электронной микроскопии (РЭМ) показало, что основной причиной изменения свойств композита может быть изменение морфологии надмолекулярной структуры ПТФЭ и характера межмолекулярного взаимодействия, обусловленного нарушением упорядоченности и плотности упаковки цепей при введении частиц наномодификаторов.

Исследование холодных сколов и поверхностей трения образцов нанокомпозитов проводили на растровом электронном микроскопе Jeol JCM-5700. Результаты исследования (рис. 3) показывают, что полимерная матрица разрабатываемого нанокомпозита имеет неоднородную ламеллярную структуру, наблюдаются области, где присутствуют крупные и мелкие гранулы технического углерода, а также неупорядоченная структура мезофазы. Можно полагать, что технология холодного прессования и свободного спекания с механоактивацией компонен-

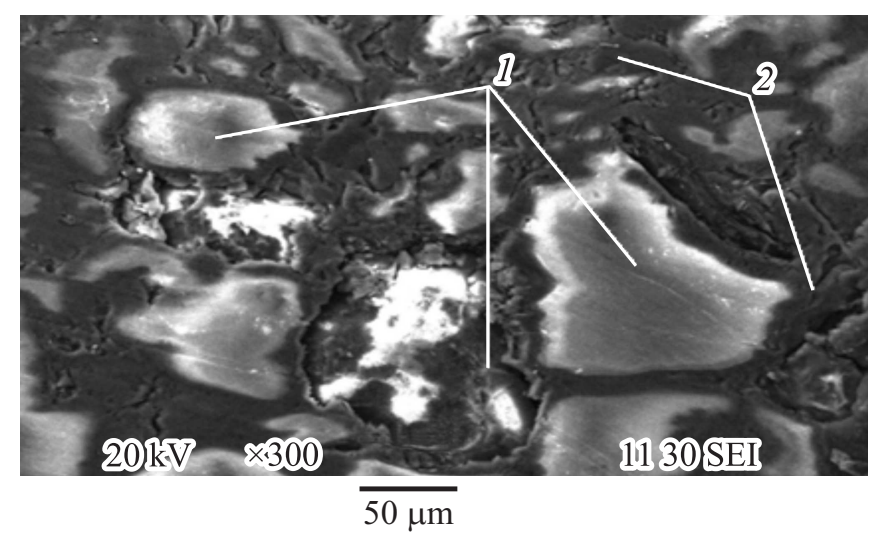

Рис. 3. Микрофотография скола образца нанокомпозита ПТФЭ с $2.0 \mathrm{wt} . \%$ ТУ $-\mathrm{N}-220$ и $4.0 \mathrm{wt} . \%$ диоксида кремния БС-120: 1 - гранулы технического углерода, 2 - ламеллярная структура полимерной матрицы. 
Содержание химических элементов в нанокомпозите

\begin{tabular}{c|c|c|c|c|c|c|c|c|c}
\hline \multirow{2}{*}{$\begin{array}{c}\text { Состав } \\
\text { наполнителей }\end{array}$} & \multicolumn{9}{c|}{ Содержание элементов в ПКМ, wt.\% } \\
\cline { 2 - 9 } & \multicolumn{3}{|c|}{ в объеме образца } & \multicolumn{5}{|c}{ в приповерхностном слое } \\
\cline { 2 - 9 } & $\mathrm{F}$ & $\mathrm{C}$ & $\mathrm{O}$ & $\mathrm{Si}$ & $\mathrm{F}$ & $\mathrm{C}$ & $\mathrm{O}$ & $\mathrm{Si}$ & $\mathrm{Fe}$ \\
\hline TУ N-220 - 2.0 wt.\%+4.0 wt.\% БC-120 & 73.65 & 20.79 & 2.48 & 3.08 & 66.49 & 18.52 & 6.35 & 2.03 & 6.61
\end{tabular}

тов в высокоскоростном механоактиваторе недостаточно эффективна для обеспечения однородного распределения компонентов в полимерной матрице и получения однородной структуры, что приводит к значительному снижению механических и триботехнических свойств нанокомпозитов. С целью устранения названного недостатка было принято решение подвергать гранулы технического углерода предварительному ультразвуковому воздействию с частотой ультразвуковых колебаний $25 \mathrm{kHz}$ и амплитудой ультразвуковых колебаний $10 \mu \mathrm{m}$. Для оценки влияния ультразвуковой обработки на измельчение гранул технического углерода и равномерность его распределения в полимерной матрице изготавливали образцы с концентрацией мономодификатора ТУ марки N-220 - 2.0 wt. $\%$.

Испытания образцов нанокомпозитов на машине трения марки УМТ2168 показали, что скорость изнашивания композиционного материала на основе ПТФЭ, изготовленного с использованием энергии ультрозвуковых колебаний, в течение $3 \mathrm{~h}$ при контактном давлении $2.66 \mathrm{MPa} \mathrm{и} \mathrm{скорости} \mathrm{скольжения} 1.2 \mathrm{~m} / \mathrm{s}$ без смазочного материала снизилась на $20.1 \mathrm{wt} \%$ и составила $6.6 \cdot 10^{-4} \mathrm{~g} / \mathrm{h}$. При увеличении длительности испытания до $6 \mathrm{~h}$, скорость изнашивания нанокомпозита снижается в среднем на $27 \%$.

Из микрофотографии поверхности трения (рис. 4) видно, что структура нанокомпозита с мономодификатором ТУ, активированным воздействием энергии ультразвуковых колебаний, становится более плотной и однородной,

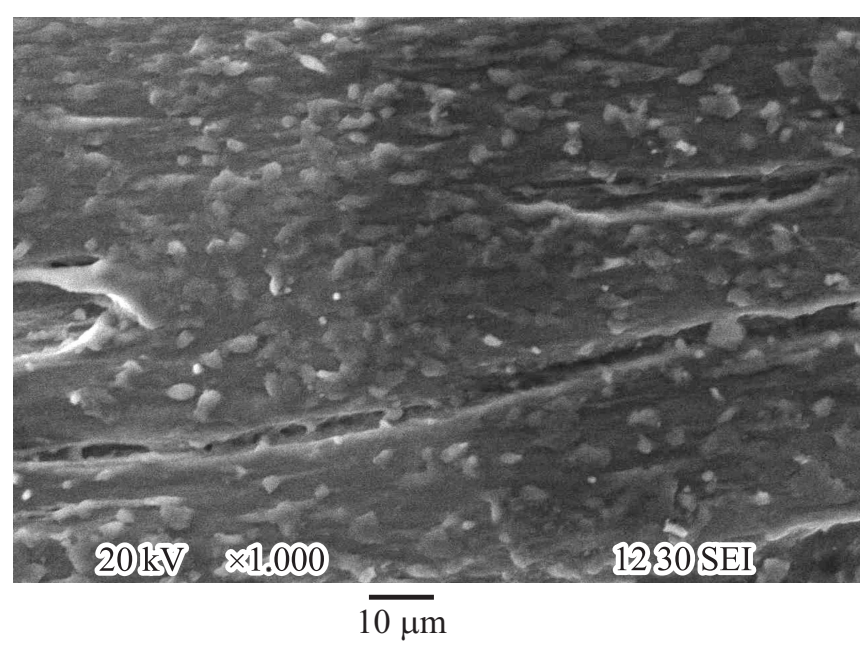

Рис. 4. Микрофотография поверхности трения образца разрабатываемого нанокомпозита. в которой отсутствуют явно выраженные локальные области с крупными гранулами технического углерода и дефектными структурами мезофазы.

Исследование элементного состава нанокомпозита показало, что после испытаний на трение и износ концентрация элементов в поверхностном слое в зоне дорожки трения отличается от содержания этих элементов вне зоны трения. Установлено, что значительно увеличилось содержание кислорода при одновременном уменьшении концентрации фтора, углерода и кремния. При этом в полимерной матрице обнаружено наличие железа в количестве 6.6 wt.\% (см. таблицу).

Значительное (в 2.6 раза) увеличение содержания кислорода вследствие фрикционного взаимодействия свидетельствует об интенсивном развитии окислительных процессов. Наличие железа в количестве, соизмеримом с количеством кислорода после фрикционного взаимодействия, можно считать результатом процесса массопереноса наночастиц железа с поверхности металлического контртела.

Таким образом, при исследовании надмолекулярной структуры и элементного состава нанокомпозита с наномодификаторами различной природы в процессе фрикционного взаимодействия с металлическим контртелом развиваются процессы структурной самоорганизации [12], включая миграцию молекул в тонком приповерхностном слое в зоне трения, окислительные процессы и перенос наночастиц железа в поверхностный слой полимерного композита.

\section{Заключение}

Результаты комплексных исследований структуры, механических и триботехнических свойств разрабатываемых нанокомпозитов на основе ПТФЭ и анализ результатов других исследований $[13,14]$ показали, что модифицирование полимера наномодификаторами различной химической природы позволяет синтезировать нанокомпозиты, отличающиеся более высокой износостойкостью при трении без смазочного материала и работоспособностью в широком интервале положительных и отрицательных температур при значительных динамических нагрузках.

Полученные результаты исследований позволяют также сделать вывод о том, что применение разрабатываемых нанокомпозитов для изготовления уплотнительных элементов герметизирующих устройств, например осей направляющих и опорных катков гусеничных машин 
(ГМ) позволяют значительно повысить работоспособность и ресурс ГМ различного назначения.

Работа выполнена при финансовой поддержке РФФИ в рамках научного проекта 16-58-00037-,„Бел-а“.

\section{Список литературы}

[1] Охлопкова А.А., Сидоренко Т.Н., Виноградов А.В. // Трение и износ. 1996. Т. 17. № 4. С. 550-553.

[2] Mashkov Yu.K., Kalistratova L.F., Leont'ev A.N., Mamaev O.A., Lipina N.A. // Трение и износ. 2002. Т. 23. № 2. C. $181-187$.

[3] Машков Ю.К., Кропотин О.В. Трибофизика и структурная модификация материалов трибосистем. Омск: Изд-во ОмГТУ, 2009. 324 c.

[4] Wang C. // Progr. Polymer Sci. 2004. N 29. P. 1079-1141.

[5] Машков Ю.К. // Самоорганизация и структурное модифицирование в металлополимерных трибосистемах. Омск: Изд-во ОмГТУ, 2013. 232 с.

[6] Машков Ю.К., Кропотин О.В., Кургузова О.А. Пат. 2525492. РФ МПК C08L 27/18; Заявитель и патентообладатель Федеральное государственное бюджетное образовательное учреждение высшего профессионального образования „Омский государственный технический университет“. № 2012146766/05; заявл. 01.11.2012; опубл. 20.08.2014. Бюл. № 23. 4 c.

[7] Машков Ю.К., Кропотин О.В., Шилько С.В., Егорова В.А., Чемисенко О.В. // Материаловедение. 2015. № 1. C. $22-25$.

[8] Кропотин О.В., Машков Ю.К., Егорова В.А., Кургузова O.A. // ЖТФ. 2014. Т. 84. Вып. 5. С. 66-70.

[9] Технические условия ТУ 3841558-97. Технический углерод.

[10] Машков Ю.К., Кропотин О.В. Егорова В.А., Кургузова O.A. // Пат. на изобретение № 2546161. РФ МПК C08J 5/00. № 2013125074/05; заявл. 29.05.2013; опубл. 10.04.2015. Бюл. № 10.

[11] Машков Ю.К., Макиенко. В.А., Малий О.В. // Пат. на изобретение № 2603673. РФ МПК С08Ј 5/00. № 2013125074/05; заявл. 29.05.2013; опубл. 10.04.2015. Бюл. № 33.

[12] Mashkov Y.K. // J. Friction and Wear. 2012. Vol. 33. N 5. P. 354-358.

[13] Weber D., Haas W. // Sealing Technology. February 2007. P. 7-12.

[14] Mattews F.L., Rawling R.D. Composite Materials: Engineering and Science. M: Техносфера, 2004. 408 c. 